\title{
The Impact of Financial Report Inquiry on Financial Restatement
}

\author{
Qinghui Dai and Xiang Xiao*
}

\author{
School of Economics and Management, Beijing Jiaotong University, China, 100044 \\ *Corresponding author.Email:xxiao@bjtu.edu.cn
}

\begin{abstract}
This article takes the financial restatement of listed companies as the searching point, test the regulatory effect of the financial report inquiry letter issued by the stock exchange. The research shows that: listed companies that received the inquiry letter were more likely to have financial misstatements and financial restatements. In order to ensure the robustness of the research conclusions, we conducted PSM on the inquiried company and non_inquiried company. The conclusion still holds. Using property rights and analyst tracking as the adjustment variables, we found that stateowned companies and more analyst tracking companies will strengthen the positive correlation between inquiries and financial restatements.
\end{abstract}

Keywords: Financial report inquiry letter, Financial restatement, SOEs, Analyst tracking.

\section{INTRODUCTION}

At present, there is still a big gap between our capital market and foreign mature markets, and the selfrestraint and mutual checks and balance mechanisms of market entities have not yet effectively formed. In 2015, the abnormal fluctuations of skyrocketing and falling sharply occurred in our stock market, which further showed that our country's A-share market still has validity defects. At the same time, corporate financial frauds are becoming more frequent, and it seriously infringes on the interests of investors. For example: "Kangmei Pharmaceutical's 30 billion cash disappeared", "Zhangzidao scallop escaped", "Oriental Jinyu Crazy Stone" etc. These events all reflect that supervision is still a shortcoming of our capital market. Since the 18th National Congress of the Communist Party of China, Chairman Xi Jinping has repeatedly emphasized the need to strengthen market supervision and promote market supervision reform and innovation. In the 19th National Congress of the Communist Party of China, Chairman Xi Jinping has continued to propose continuous improvement of the market supervision system, innovative supervision methods, and prevention of major risks. Regulatory innovation is imperative.

The "Several Opinions on Further Promoting the Healthy Development of Capital Markets" issued by the State Council in 2014 pointed out the need to strengthen the market dominance of stock exchanges. In order to better play the front-line supervision function, at the end of 2014, the Shanghai Stock Exchange and the Shenzhen Stock Exchange began to publicly issue letters of inquiry on their official websites. The inquiry system is subject to in-event and post-event supervision. As the front line of supervision, the exchange's supervision inquiries can prompt relevant companies to more fully and completely disclose information, clarify doubts, fully protect investors' right to know, and prevent and resolve market risks.

The financial reports and publicity documents independently disclosed by listed companies are the most direct source of information for investors and other stakeholders in the market. In order to alleviate decision-making errors caused by information asymmetry and ensure the orderly operation of the capital market, the information disclosure system requires listed companies to disclose relevant information truthfully, accurately and completely. Whether the information disclosure of listed companies is in compliance with regulations has always attracted the attention of regulators and investors. As the front line of supervision, the stock exchange is one of the main ways for regulatory agencies to supervise the accounting information of listed companies by issuing financial report inquiry letters. According to statistics, the amount and proportion of inquiry functions related to financial reports are on the rise year by year. As an 
important means for the innovation of government supervision methods, the implementation of the financial report inquiry system has attracted the attention of scholars.

Financial restatement is an important indicator that reflects the quality of corporate accounting information disclosure. When a company's accounting information is subject to objective misstatement and subjective manipulation, financial restatement is more likely to occur. Relevant data shows that in recent years, financial restatements of listed companies in my country have increased and become more frequent. From 2010 to 2018 , the average annual growth rate of financial restatements in the A-share market was as high as $29.2 \%$. More and more common financial restatements will not only produce negative market reactions, but in the long run, it will be more likely to cause systemic financial risks. Whether the emergence and implementation of the regulatory inquiry system can improve the quality of accounting information disclosure and curb the financial restatement behavior of enterprises is a question worthy of discussion.

\section{THEORETICAL ANALYSIS AND RESEARCH HYPOTHESIS}

From the perspective of corporate agency costs, compared with external audits, stock exchange regulatory inquiries are initiated by an independent third party. Companies have no independent right to choose and can better reduce the agency costs. Therefore, companies are willing to Cooperate with the exchange's regulatory inquiries. If the company that receives the inquiry letter still has opportunistic behavior regarding accounting information, the company will face more severe penalties, and will face more stringent external audits (Peng Wen et al., 2019), increase the probability of being issued a non-standard audit opinion (Gietzmann and Pettinicchio, 2014; Chen Yunsen et al., 2018), and also face greater Regulatory pressures and litigation risks. Therefore, companies that receive the inquiry letter are more willing to take the initiative to improve the quality of their accounting information (robustness, reliability, and comparability). This inference has also been confirmed by scholars(Johnston and Petacchi, 2017; Bozanic et al., 2018; Robinson et al., 2011; Sheng Haoyu, 2018; Chen Chunxiao, 2018; Duan et al., 2020). High-quality accounting information means fewer financial misstatements Therefore, we hypothesize:

H1a: The financial report inquiry letter can effectively reduce the probability of the company's financial restatement.

Based on the signal transmission theory, the companies that received the inquiry letter conveyed the signals that the quality of information disclosure is poor, the audit quality is not up to the standard, and the corporate governance has loopholes. Such companies themselves are prone to financial restatements. In addition, if there are errors in the financial report, it may cause information users to make wrong decisions, which is not conducive to the development of the company. Therefore, if the company receives an inquiry letter involving the correction of financial report errors, it will be more proactive in financial reporting Restate.

Moreover, the research conclusions show that the regulatory effects of my country's regulatory agencies are not significant. For example, after a violation company is punished, it hides or even encourages true earnings management. At the same time, the financial report inquiry letter is not an administrative punishment supervision, and it does not impose substantial penalties on the company, and the inquiry letter with a lower severity of the problem will not attract the attention of the receiving company. Therefore, the inquiry letter has played an incremental role in financial information, it can only alleviate information asymmetry, and it's hardly affect the company's financial irregularities. Therefore, we propose the opposite hypothesis:

$\mathrm{H} 1 \mathrm{~b}$ : The financial report inquiry letter is positively related or irrelated to the company's financial restatement.

\section{RESEARCH DESIGN}

\subsection{Samples and Data}

The regulatory inquiry system of the stock exchange has been implemented since the end of 2014. Since 2015, the Shanghai Stock Exchange and the Shenzhen Stock Exchange have issued a large number of inquiry letters. Therefore, this article selects all the A-share listed companies from 2015 to 2019 as the research sample. The inquiry data comes from the CNRDS database, and the rest of the data comes from the CSMAR database. After excluding the financial industry, ST, *ST, and samples with missing data, the final research sample is 12583 , of which 1421 samples received financial report inquiry letters.

\subsection{Variable Definition and Research Model}

In order to verify the impact of the financial report query on the company's financial restatement, we constructed model (1) as follows:

$$
\begin{aligned}
\text { RESTATE }_{i, t}=\gamma_{0}+\gamma_{1} \text { INQUIRY }_{i, t}+\gamma_{2} \text { SIZE }_{i, t}+\gamma_{3} \text { ICI }_{i, t} \\
+\gamma_{4} \text { LEV }_{i, t}+\gamma_{5} \text { ROA }_{i, t}+\gamma_{6} \text { GROWTH }_{i, t} \\
+\gamma_{7} I N V_{i, t}+\gamma_{8} O C F_{i, t}+\gamma_{9} \operatorname{STATE}_{i, t} \\
+\gamma_{10} B I G 4_{i, t}+\gamma_{11} T O P 1_{i, t}+\sum I N D_{i}+\varepsilon_{i, t}
\end{aligned}
$$

Among them, the dependent variable is financial restatement. When company $i$ has a financial restatement in year $t$, the value is 1 , otherwise it is 0 . 
Table 1. Descriptive statistics of the main variables

\begin{tabular}{|c|c|c|c|c|c|c|c|c|}
\hline \multicolumn{7}{|c|}{ Panel A: Descriptive statistics of the main variables } & \multicolumn{2}{|c|}{ Panel B: Inquiry Distribution } \\
\hline Var & $\mathrm{N}$ & Mean & St.Dev & Min & Median & Max & Year & $\mathrm{N}$ \\
\hline RESTATE & 12583 & 0.228 & 0.419 & 0 & 0 & 1 & 2015 & 109 \\
\hline INQUIRY & 12583 & 0.113 & 0.317 & 0 & 0 & 1 & 2016 & 205 \\
\hline SIZE & 12583 & 22.32 & 1.288 & 20.04 & 22.15 & 26.27 & 2017 & 346 \\
\hline ICI & 12583 & 6.252 & 1.188 & 0 & 6.495 & 6.694 & 2018 & 442 \\
\hline LEV & 12583 & 0.420 & 0.200 & 0.0616 & 0.409 & 0.887 & 2019 & 319 \\
\hline ROA & 12583 & 0.0381 & 0.0577 & -0.245 & 0.0361 & 0.189 & TOTAL & 1421 \\
\hline GROWTH & 12583 & 0.426 & 1.079 & -0.687 & 0.159 & 7.970 & & \\
\hline INV & 12583 & 19.83 & 1.845 & 13.60 & 19.81 & 24.85 & & \\
\hline OCF & 12583 & $7.53 e+08$ & $2.41 \mathrm{e}+09$ & $-2.30 \mathrm{e}+09$ & $1.60 \mathrm{e}+08$ & $1.80 \mathrm{e}+10$ & & \\
\hline STATE & 12583 & 0.351 & 0.477 & 0 & 0 & 1 & & \\
\hline BIG4 & 12583 & 0.0585 & 0.235 & 0 & 0 & 1 & & \\
\hline TOP1 & 12583 & 33.95 & 14.62 & 0.290 & 31.92 & 89.99 & & \\
\hline
\end{tabular}

Table 2. Regression results of the impact of inquiry on restatement

\begin{tabular}{|c|c|c|c|c|c|c|c|c|}
\hline \multicolumn{7}{|c|}{ Panel A: Descriptive statistics of the main variables } & \multicolumn{2}{|c|}{ Panel B: Inquiry Distribution } \\
\hline Var & $\mathrm{N}$ & Mean & St.Dev & Min & Median & Max & Year & $\mathrm{N}$ \\
\hline RESTATE & 12583 & 0.228 & 0.419 & 0 & 0 & 1 & 2015 & 109 \\
\hline INQUIRY & 12583 & 0.113 & 0.317 & 0 & 0 & 1 & 2016 & 205 \\
\hline SIZE & 12583 & 22.32 & 1.288 & 20.04 & 22.15 & 26.27 & 2017 & 346 \\
\hline ICI & 12583 & 6.252 & 1.188 & 0 & 6.495 & 6.694 & 2018 & 442 \\
\hline LEV & 12583 & 0.420 & 0.200 & \begin{tabular}{|l}
0.0616 \\
\end{tabular} & 0.409 & 0.887 & 2019 & 319 \\
\hline ROA & 12583 & 0.0381 & 0.0577 & -0.245 & 0.0361 & 0.189 & TOTAL & 1421 \\
\hline GROWTH & 12583 & 0.426 & \begin{tabular}{|l|}
1.079 \\
\end{tabular} & -0.687 & 0.159 & 7.970 & & \\
\hline INV & 12583 & 19.83 & 1.845 & 13.60 & 19.81 & 24.85 & & \\
\hline OCF & 12583 & $7.53 e+08$ & $2.41 \mathrm{e}+09$ & $-2.30 \mathrm{e}+09$ & $1.60 \mathrm{e}+08$ & $1.80 \mathrm{e}+10$ & & \\
\hline STATE & 12583 & 0.351 & 0.477 & 0 & 0 & 1 & & \\
\hline BIG4 & 12583 & 0.0585 & 0.235 & 0 & 0 & 1 & & \\
\hline TOP1 & 12583 & 33.95 & 14.62 & \begin{tabular}{|l|}
0.290 \\
\end{tabular} & 31.92 & 89.99 & & \\
\hline
\end{tabular}

Table 3. Robustness Test1: Regression results based on PSM

\begin{tabular}{|c|c|c|c|c|c|c|}
\hline & \multicolumn{2}{|l|}{ Full sample } & \multicolumn{2}{|c|}{ Shenzhen Stock Exchange } & \multicolumn{2}{|c|}{ Shanghai Stock Exchange } \\
\hline & RESTATE & $Z$ & RESTATE & $z$ & RESTATE & $Z$ \\
\hline INQUIRY & $2.448 * * *$ & 26.12 & $2.643 * * *$ & 20.92 & $2.233^{* * *}$ & 15.07 \\
\hline SIZE & 0.000 & 0.19 & 0.000 & 00.19 & 0.000 & 0.25 \\
\hline ICI & $-0.001^{* * *}$ & -4.71 & $-0.001^{*}$ & -1.76 & $-0.001 * * *$ & -3.52 \\
\hline LEV & -0.202 & -0.90 & $-0.661 * *$ & -2.21 & 0.438 & 1.24 \\
\hline ROA & 0.0 .97 & 0.19 & -0.470 & -0.76 & 0.501 & 0.56 \\
\hline GROWTH & $-0.046^{*}$ & -1.90 & -0.054 & -1.47 & $-0.053^{*}$ & -1.65 \\
\hline INV & -0.000 & -0.94 & -0.000 & -0.61 & -0.000 & -0.13 \\
\hline OCF & $0.000 * * *$ & 2.30 & 0.000 & 1.50 & $0.000^{*}$ & 1.86 \\
\hline STATE & 0.019 & 0.20 & -0.167 & -1.31 & $0.253^{*}$ & 1.72 \\
\hline BIG4 & -0.227 & -1.01 & -0.012 & -0.04 & $-0.900 *$ & -1.90 \\
\hline TOP1 & $-0.009 * * *$ & -2.77 & -0.005 & -1.12 & $-0.016^{* * *}$ & -2.95 \\
\hline Constant & $-1.575^{* * *}$ & -8.05 & $-1.985 * * *$ & -6.88 & $-1.410 * * *$ & -4.99 \\
\hline $\mathrm{N}$ & \multicolumn{2}{|l|}{4056} & \multicolumn{2}{|l|}{2688} & \multicolumn{2}{|l|}{1368} \\
\hline Pseudo $\mathrm{R}^{2}$ & \multicolumn{2}{|l|}{0.2091} & \multicolumn{2}{|l|}{0.2254} & \multicolumn{2}{|l|}{0.1964} \\
\hline IND & \multicolumn{6}{|l|}{ Controlled } \\
\hline YEAR & \multicolumn{6}{|l|}{ Controlled } \\
\hline
\end{tabular}

Table 4. Robustness Test2: INQUIRY with a lag period

\begin{tabular}{|c|c|c|c|c|c|c|c|c|c|c|c|}
\hline & INQUIRY & SIZE & ICI & LEV & ROA & GROWTH & INV & OCF & STATE & BIG4 & TOP1 \\
\hline \multirow{2}{*}{ RESTATE } & $0.679^{* * *}$ & $-0.000^{* *}$ & $-0.000^{* *}$ & 0.040 & $1.517^{* * *}$ & $-0.094^{* * *}$ & 0.000 & $0.000^{* *}$ & -0.036 & $-0.184^{*}$ & $-0.004^{* *}$ \\
& $(9.00)$ & $(-2.48)$ & $(-2.21)$ & $(0.29)$ & $(3.35)$ & $(-3.72)$ & $(1.10)$ & $(2.28)$ & $(-0.69)$ & $(-1.65)$ & $(-2.24)$ \\
\hline
\end{tabular}


The independent variable is the inquiry letter INQUIRY. Drawing on the research method of Johnston and Petacchi (2017), when the company receives the annual report inquiry letter, semi-annual report inquiry letter and quarterly report inquiry letter, we define INQUIRY as 1 , otherwise it is 0 . IL_NUM is the collected function amount, which is the logarithm after the company receives the financial report inquiry function amount in $\mathrm{t}$ year plus one. Control variables include company size SIZE, internal control level ICI, solvency LEV, profitability ROA, sales growth rate GROWTH, operating complexity INV, operating cash flow OCF, property rights STATE, firm size BIG4, and equity concentration TOP1.

\section{EMPIRICAL RESULTS AND DISCUSSION}

\subsection{Descriptive Statistics}

Table 1 reports the descriptive statistics of main variables. The mean of RESTATE is 0.228 , indicating that there are $22.8 \%$ of listed companies reported financial restatements, it is a big weight. The mean of INQUIRY is 0.113 , indicating that there are $11.3 \%$ of listed companies received the inquiry letter. This number is less than the RESTATE, it shows that the supervision needs to be improved. Panel B reports the total amount of inquiry letter issued by the Shenzhen Stock Exchange and the Shanghai Stock Exchange each year.

\subsection{Empirical Regression Analysis}

We plot the logit results of model in Table 2 to reveal the impact of inquiry on restatement. It is shown that the inquiry and restatements are significantly positively correlated at the level of $1 \%$, no matter it's a full sample or Shanghai Stock Exchange sample or the Shenzhen Stock Exchange sample. We can conclude that it is easier for the inquired company to make financial restatements, which supports our proposed hypothesis H1b.

\subsection{Robustness Test}

\subsubsection{PSM Test}

In order to reduce the impact of the difference in characteristics between the inquiried company and non_inquiried company, we conducted PSM on the two types of companies. The results are shown in Table 3. It shows that the inquiries and financial restatements are still significantly positively correlated. The original conclusion still holds.

\subsubsection{Reverse Causality Test}

In order to avoid the endogenous problem of negative causality between the independent variable and the dependent variable, we used the INQUIRY with a lag period as the independent variable to conduct logit again; the results are shown in Table 4. The original conclusion still holds.

\subsection{Further Analysis}

\subsubsection{Long-term Effect Analysis}

The main purpose of inquiry supervision is to increase the intensity of information disclosure, reduce the degree of information asymmetry between companies and information users, improve the quality of disclosed financial reports, and reduce investment risks. However, because it is a non-punitive supervision, the supervision is weak, and the restraint on the company is relatively small. There are quite a few companies that do not reply on time or answer the wrong questions. This leads to the stock exchanges having to ask questions over and over again for the same question until the problem is solved. Therefore, it may take some time for the actual effects of inquiry supervision to be manifested. We use the data from the year 2015 to 2018 as samples, to examine the annual lag effect. The empirical results show that even if the dependent variable is delayed by 3 years, the inquiry and financial restatement are still significantly positively correlated, but the correlation coefficient is decreasing year by year. Due to space limitations, this result is not listed.

\subsubsection{Property Analysis}

Many scholars have shown that the relationship between the company and the government will affect the regulatory effect of punitive supervision. Anderson (2000) believes that when a company with close ties to the government violates regulations, the relevant penalties cannot be effectively implemented. Stateowned enterprises are ultimately controlled by government agencies and have a natural political connection, while politically connected companies will weaken the efficiency of law enforcement by regulatory agencies by affecting the timeliness of investigation and punishment of violations (Xu Nianxing et al., 2013). The inquiry supervision of stock exchanges is a nonpenalty supervision, and the influence of the relationship between government and enterprise on inquiry supervision has not been studied yet. Empirical results show that analyst tracking plays a positive role in the influence of inquiry on financial restatement. Due to space limitations, this result is not listed. 


\section{CONCLUSION}

This article uses A-share listed companies as samples to examine the impact of stock exchange inquiries supervision on corporate financial restatements. The empirical conclusions show that companies that receive the inquiry letter are more likely to have financial restatements, and SOEs and analyst tracking play a positive role in this regulation. According to logic, if the supervision is effective, the quality of the financial report of the company that receives the inquiry letter will be improved and the probability of financial restatement will decrease after the "underlying" type of inquiry. However, in the further examination of this article, the company that received the inquiry letter as a sample, and the last time the inquiry letter was received as the time node, examine the influence of the inquiry on the financial restatement. The results show that there is still a significant positive correlation between the two. It can be seen that under the existing samples, the effect of inquiry supervision on financial misstatement is not obvious. This may be related to the shorter measurement time.

\section{REFERENCES}

[1] Chen Yunsen, Deng Yilu and Li Zhe, Effectiveness of the Front-line Regulation of the Chinese Stock Exchanges: Evidence From Comment Letters, Journal of Management World, 2019, 35(03):169185+208. DOI: 10.19744/j.cnki.11-235/f.2019.0042
[2] ZHAI Shu-ping, WANG Min, HAN Xian, Financial Inquiry Regulation of Exchanges and Accounting Information Comparability: Direct Effect and Spillover Effect, Contemporary Finance \& Economics, 2020,431(10):124-137. DOI: 10.13676/j.cnki.cn36-1030/f.2020.10.012

[3] Johnston, R. and R. Petacchi, Regulatory Oversight of Financial Reporting: Securities and Exchange Commission Comment Letters, Contemporary Accounting Research, 2017,34(2): 1128-1155. DOI: $10.1111 / 1911-3846.12297$

[4] Gietzmann, M. B. and A. K. Pettinicchio, External Auditor Reassessment of Client Business Risk Following the Issuance of a Comment Letter by the SEC, European Accounting Review, 2014,23(1):57-85. DOI: $10.1080 / 09638180.2013 .774703$

[5] Peng Wen, Zhang Limin, Zhong Kai, Li Laifang, Study on the Effectiveness of Inquiry Letters: Evidence from Auditors' Behavior, 2019,32(04),1730. DOI:10.3969/j.issn.1672-0334.2019.04.002

[6] Wang Qian., Determinants of Segment Disclosure Deficiencies and the Effect of the SEC Comment Letter Process, Journal of Accounting and Public Policy, 2016,35(2): 109-133. DOI: 10.1016/j.jaccpubpol.2015.11.005 